\author{
Leila El Matri \\ Aude Ambresin \\ Daniel F. Schorderet \\ Aki Kawasaki \\ Mathias W. Seeliger \\ Andreas Wenzel \\ Yvan Arsenijevic \\ François-Xavier Borruat \\ Francis L. Munier
}

\section{Phenotype of three consanguineous Tunisian families with early-onset retinal degeneration caused by an R91W homozygous mutation in the RPE65 gene}

Received: 21 March 2005

Revised: 13 July 2005

Accepted: 18 July 2005

Published online: 28 February 2006

(C) Springer-Verlag 2006
M. W. Seeliger

Retinal Electrodiagnostics Research

Group, Department of Ophthalmology,

University of Tübingen,

Tübingen, Germany

A. Wenzel

Opthalmology, Retinal Cell Biology,

University Hospital of Zurich,

Zurich, Switzerland

L. El Matri and A. Ambresin contributed equally to this work.

L. El Matri

Hedi Rais Institute of Ophthalmology, Tunis, Tunisia

A. Ambresin $(\bowtie) \cdot D$. F. Schorderet .

A. Kawasaki - Y. Arsenijevic ·

F. Borruat · F. L. Munier $(\bowtie)$

Department of Ophthalmology,

Jules Gonin Eye Hospital,

University of Lausanne,

1004 Lausanne, Switzerland

e-mail: aude.ambresin@ophtal.vd.ch

Tel.: +49-41-216268589

Fax: +49-41-216268544

e-mail: francis.munier@ophtal.vd.ch

D. F. Schorderet

Institut de Recherche

en Ophtalmologie,

Sion, Switzerland

\begin{abstract}
Purpose: To identify the genetic defect and to phenotype three consanguineous Tunisian families presenting with early-onset retinal degeneration (EORD). Methods: All accessible family members were included. They underwent blood sampling and ophthalmological examination including, when possible, full-field ERG and pupillometry. A genomewide linkage analysis was initiated. Mutation analysis of the RPE65 gene within the linked interval was performed by bi-directional sequencing. Results: Eleven out of 53 examined members were clinically affected with an EORD. Linkage analysis
\end{abstract}

revealed a maximal lod score of 4.02 $(\theta=0.1)$ for the marker D1S207 on 1p31. Mutational screening of the RPE65 gene identified a homozygous R91W mutation co-segregating with the disease in all affected individuals. Eleven homozygotes had nystagmus and acuities ranging from CF to NLP. Two retinal patterns were identified: pattern 1 presented midperipheral deep white dot deposits and virtually no clumped pigmentation, whereas pattern 2 showed midperipheral pigmented clumps without any white deposits. Homozygotes had no detectable full-field ERG and an abnormal pupillary light reflex. Eleven heterozygotes had normal visual function. Conclusion: We identified and characterised an endemic form of early onset rod-cone dystrophy in a consanguineous population from northeastern Tunisia, due to the prevalence of a single RPE65 mutation. Two funduscopic patterns were identified: white dot deposits in earlier stages and clumped pigment in later stages.

\section{Introduction}

Early-onset retinal dystrophy (EORD) includes heterogeneous hereditary disorders sharing degeneration of both rod and cone photoreceptors [10]. At the most severe end of the spectrum of EORD and accounting for 5\% of all retinal dystrophies is Leber congenital amaurosis; a less aggressive form is juvenile retinitis pigmentosa $[6,9,25]$.
Among the different genes that have been identified to account for EORD, mutations in the RPE65 gene seem to be the most frequent $[3,12,25,30]$ (approximately $6 \%$ ) [9]. The RPE65 gene has been assigned to chromosome 1p31 [7] and encodes for a retinal pigment epitheliumspecific and highly conserved abundant $65-\mathrm{kDa}$ protein. This protein is a retinol ester-binding protein that plays an important role in the vitamin A cycle, being necessary for 
a

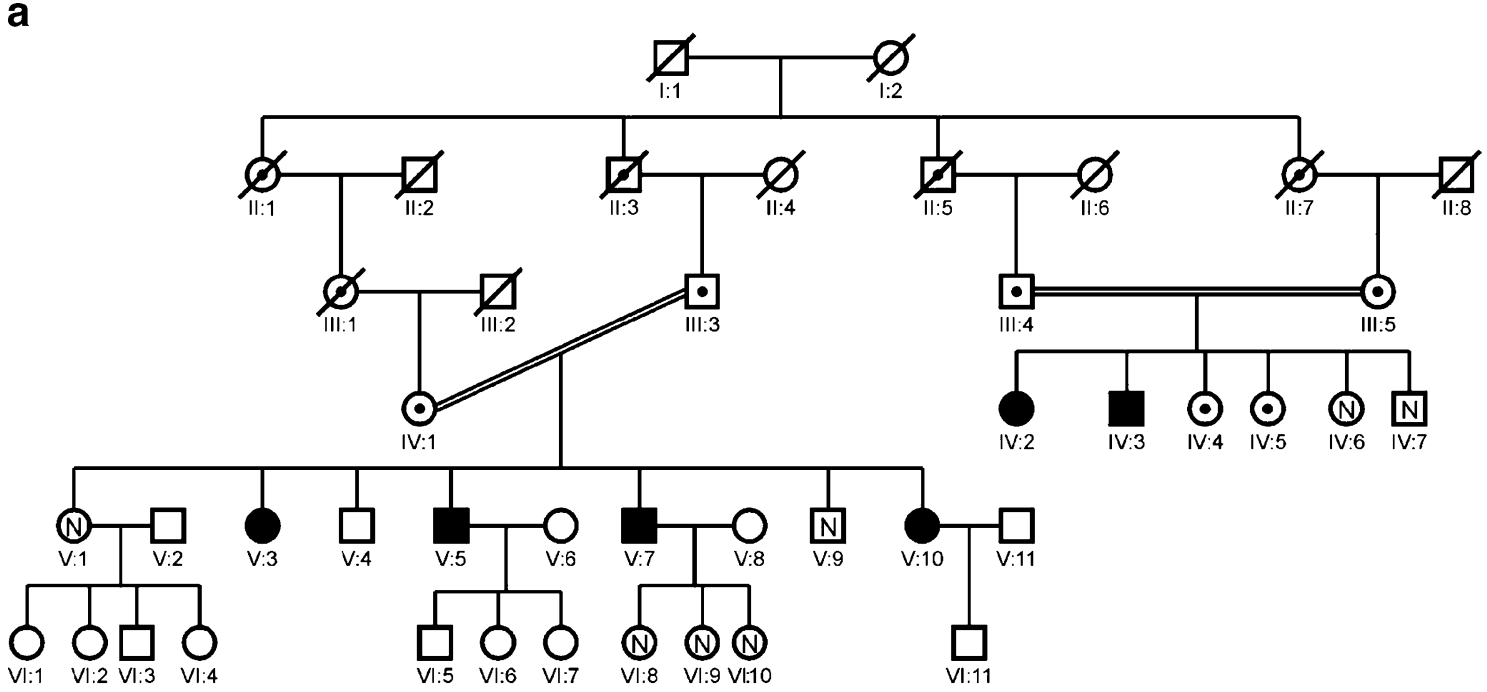

b

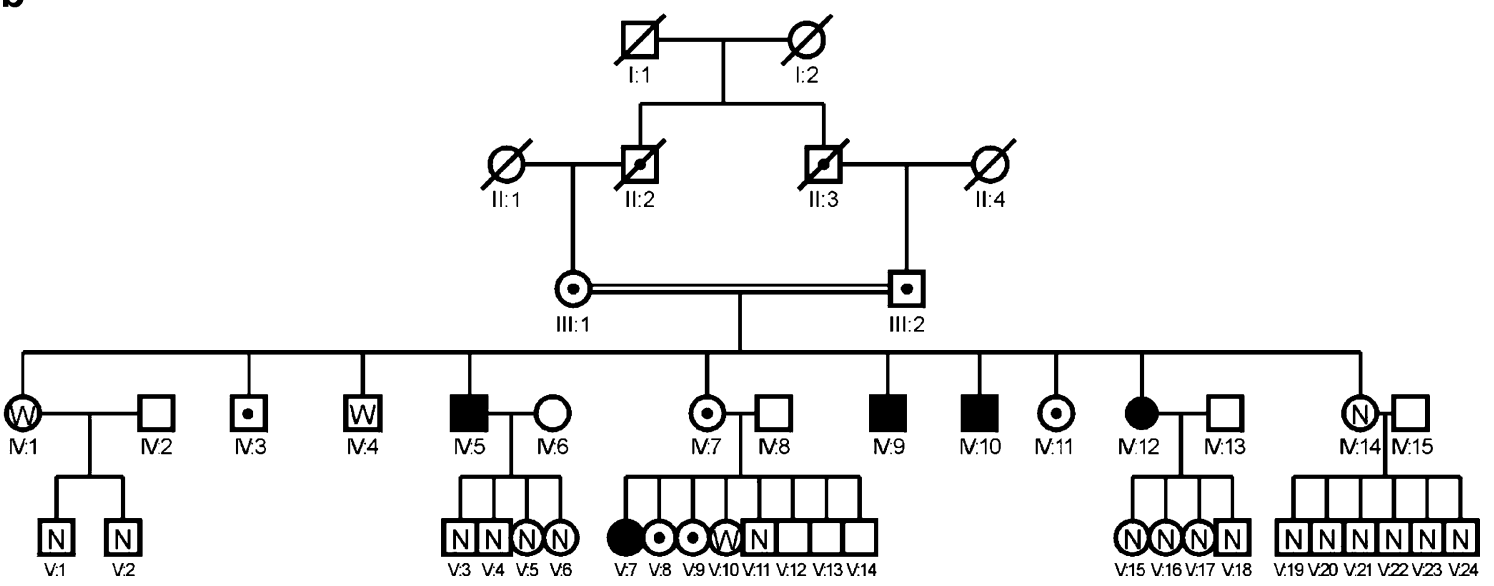

Fig. 1 a Pedigree $\mathrm{BH}$. b Pedigree BO. Filled symbols denote individuals RPE65 $5^{\mathrm{R} 91 \mathrm{~W} / \mathrm{R} 91 \mathrm{~W}}$; symbols with dots represent individuals RPE65 ${ }^{\mathrm{WT}} /{ }^{\mathrm{R} 91 \mathrm{~W}}$; $W$ open symbols show wild-type unaffected

the conversion to 11-cis retinal [7], the chromophore of the visual pigments. ${ }^{1}$

Mice and dogs lacking RPE65 gene (knock-out model) have been developed and studied [22, 28]. Histopathologic examinations of the diseased eyes from these animal models have revealed decreased accumulation of lipofuscin [11] and increased accumulation of retinyl esters in the RPE [16]. Partial functional and structural recovery of the retina after gene therapy in the RPE65 null mutation dog was recently reported [19].

The human molecular pathology of the RPE65 gene is not fully described and little is known regarding genotype/

\footnotetext{
${ }^{1}$ Moiseyev et al identified the RPE65 protein as the isomerohydrolase transforming all-trans retinyl-ester into 11-cis retinol. Moiseyev G, Chen Y, Takahashi Y, Wu BX, Ma JX. RPE65 is the isomerohydrolase in the retinoid visual cycle. Proc Natl Acad Sci U S A. 2005 Aug 30;102(35):12413-12418
}

individuals RPE65 ${ }^{\mathrm{WT}} / \mathrm{WT}$; $N$ open symbols represent the nongenotyped members with normal phenotype; plain open symbols are the non-examined members

phenotype correlations and natural history of specific disease-causing mutations $[3,5,8,20,21,25]$.

In this study three families harbouring a single RPE65 mutation were fully characterised, as precise phenotyping is likely to represent an important prerequisite for future trial of gene therapy.

\section{Patients and methods}

Fifty-three members of three consanguineous nuclear families (Fig. 1) with EORD who originated from the same village in Cap Bon, northeastern Tunisia were included in the study. They underwent complete ophthalmological examination and, when possible, fluorescein angiography, colour vision test, computerised visual field, full-field ERG and pupillometry. 
With their consent, blood samples were obtained from 26 family members.

Clinical and electrophysiological examinations

Visual acuities were tested with Snellen chart and illiterate E chart. Computerised visual fields were measured with Humphrey Systems (Program 30-3, Humphrey Field Analyzer II, San Leandro, CA, USA). Colour vision was tested using the Farnsworth D-15 saturated dichotomous test. Presence of nystagmus was evaluated. The anterior segment was examined with a slit lamp (Haag-Streit), and fundoscopy was performed by binocular indirect ophthalmoscopy. Fundus photographs and fluorescein angiography were performed with a fundus camera (Topcon). The electroretinography was performed under topical anaesthetic (tetracaine monodoses) using an ERG unit (Veritas; LKC, Gaithersburg, USA) according to the ISCEV standards (International Society for Clinical Electrophysiology of Vision). Pupillometry was carried out using a prototype portable pupillometry device (Neuroptics, Irvine, CA, USA). The device gave a 1-s diffuse light stimulus to one eye $\left(6.2 \mathrm{~mW} / \mathrm{cm}^{2}\right)$ while recording the iris and pupillary margins continuously for $1 \mathrm{~s}$ after the light stimulus. Internal software analysis automatically calculated the maximum area, minimum area, percentage of contraction amplitude, latency and velocity. Normative data based on age and baseline pupil size were provided by the manufacturer. Five measurements of the pupil light reflex per eye were obtained and averaged to minimise confounding effects from short-term variability.

\section{Molecular analysis}

Genomic DNA was isolated from peripheral blood leucocytes as described elsewhere [15]. Genotyping was performed using 396 fluorescent dye-labeled dinucleotide repeat markers -FAM, _HEX or NED (Prism Linkage
Mapping Set, Version 2; Applied Biosystems) following instructions from the manufacturer. PCR products were pooled and denatured at $90^{\circ} \mathrm{C}$ for 2 min. Markers were electrophoresed on denaturing polyacrylamide Performance Optimized Polymer 4 gels (POP-4; Applied Biosystems) on an automatic DNA sequencer (ABI-Prism 310 Genetic Analyser). Data were collected and analysed using Genescan and Genotyper software packages. Linkage analysis was performed with MLINK using equal allele frequency and a new mutation rate of $10^{-4}$.

Once linkage had been established, each of the exons of the best candidate gene was amplified by PCR as previously described. The PCR products were then screened for mutations by single-strand conformational polymorphism (SSCP) analysis. The abnormal conformers were sequenced bidirectionally.

\section{Results}

The three nuclear families belonging to two distinct pedigrees (BH and BO) are shown in Fig. 1. Eleven of the 53 examined family members were clinically affected with EORD. Blood samples were obtained from 10 of them and from 16 unaffected family members. Linkage analysis revealed a maximal lod score of $4.02(\theta=0.1)$ for marker D1S207 on chromosome 1p31, mapping close to the RPE65 gene locus. Mutational analysis of the RPE65 gene identified a homozygous R91W missense mutation (CGG to TGG) in exon 4 (Fig. 2c), co-segregating with the disease in all affected individuals. Analysis of the blood samples from the 16 clinically unaffected members revealed 12 heterozygotes RPE65 ${ }^{\mathrm{WT}} / \mathrm{R}^{1 \mathrm{~W}}$ and 4 wild-type RPE65 ${ }^{\mathrm{WT}} / \mathrm{WT}$ (Fig. 2a,b).

Details of the ten examined homozygotes are summarised in Table 1. None had signs of syndrome-associated features. They all had congenital night blindness and no photophobia. They had useful vision in the first decade of life, allowing reading acquisition, but had to learn Braille at the end of the first decade. They progressively lost vision in the third decade of life to the point of disability. They were aged $19-55$ years a

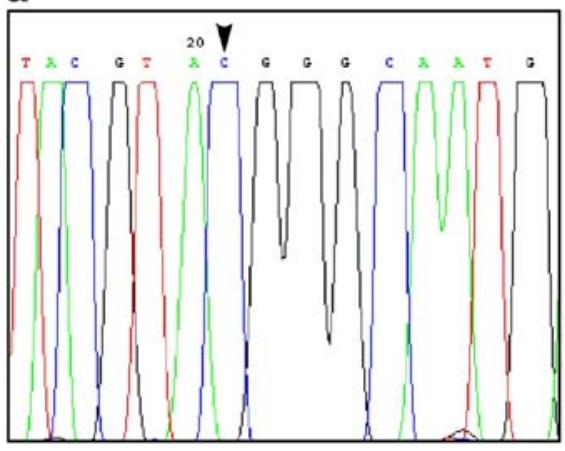

b

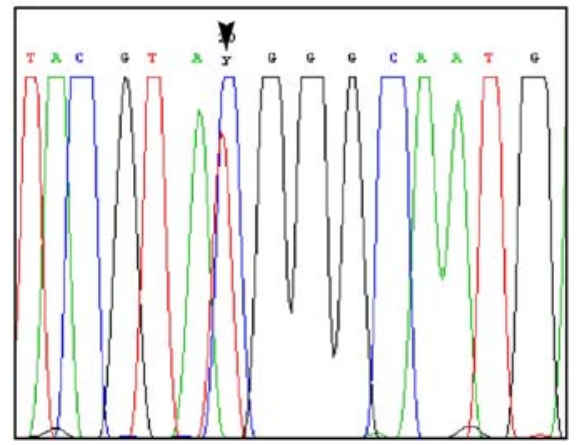

c

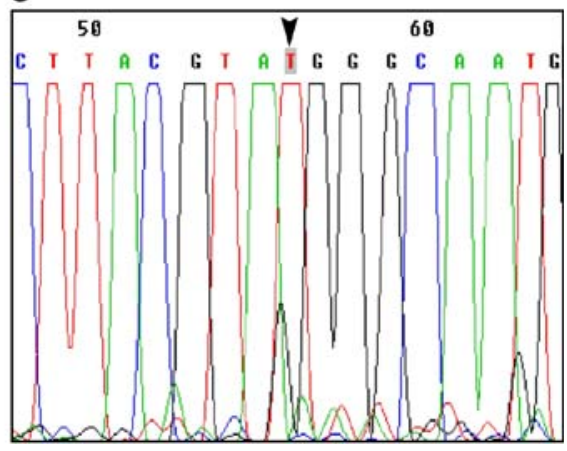

Fig. 2 Genomic sequences: missense mutation R91W (CGG to TGG) in exon 4 of the RPE65 gene. a Wild-type missense mutation RPE65 $5^{\mathrm{WT} / \mathrm{WT}}$. b Heterozygotes mutation RPE65 $5^{\mathrm{WT} / \mathrm{R} 91 \mathrm{~W}}$. c Homozygotes RPE65 $5^{\mathrm{R} 91 \mathrm{~W} / \mathrm{R} 91 \mathrm{~W}}$ 
Table 1 Details of homozygous individuals

\begin{tabular}{|c|c|c|c|c|c|c|c|c|c|c|}
\hline $\begin{array}{l}\text { Patient/ } \\
\text { age } \\
\text { (years)/ } \\
\text { sex }\end{array}$ & $\begin{array}{l}\text { Acuity } \\
\text { (ETDRS) }\end{array}$ & $\begin{array}{l}\text { Ambulatory } \\
\text { vision, } \\
\text { up to }\end{array}$ & & Lens & Macula & Disk & $\begin{array}{l}\text { Peripheral } \\
\text { pigment } \\
\text { clumps }\end{array}$ & $\begin{array}{l}\text { Retinal } \\
\text { vessels }\end{array}$ & $\begin{array}{l}\text { Fluorescein } \\
\text { angiography }\end{array}$ & Pattern \\
\hline \multicolumn{11}{|c|}{ Pedigree $\mathrm{BH}$} \\
\hline $\begin{array}{l}\text { Patient } \\
\text { IV: } \\
2 / 55 / \mathrm{F}\end{array}$ & BE:LP & $\begin{array}{l}\text { No, } \\
50 \text { years }\end{array}$ & NA & APoNSPCOcat & Atrophic & $\begin{array}{l}\text { Slight } \\
\text { pallor }\end{array}$ & ++ & Attenuated & NA & 2 \\
\hline $\begin{array}{l}\text { Patient } \\
\text { IV: } \\
\text { 3/49/M }\end{array}$ & BE:LP & $\begin{array}{l}\text { No, } \\
21 \text { years }\end{array}$ & $\begin{array}{l}\text { RE: S } \\
+3.00, \\
\text { C-3.75 } \\
\text { LE:S-1.5, } \\
\text { C-3.00 }\end{array}$ & NSPCOcat & $\begin{array}{l}\text { Atrophic, } \\
\text { RPE } \\
\text { changes }\end{array}$ & $\begin{array}{l}\text { Slight } \\
\text { pallor }\end{array}$ & ++ & Attenuated & $\begin{array}{l}\text { Confluent lobular } \\
\text { macular choriretinal } \\
\text { filling defect } \\
\text { hypofluorescence, } \\
\text { central and } \\
\text { peripheral pigment } \\
\text { clumps blockage } \\
\text { hypofluorescence }\end{array}$ & 2 \\
\hline $\begin{array}{l}\text { Patient } \\
\text { V: } \\
7 / 43 / \mathrm{M}\end{array}$ & BE:NLP & $\begin{array}{l}\text { No, } \\
30 \text { years }\end{array}$ & $\begin{array}{l}\text { RE: } \mathrm{S}+ \\
2.25, \\
\mathrm{C}-1.5 \\
\mathrm{LE}: \mathrm{S}+5.5, \\
\mathrm{C}-2.00\end{array}$ & PCOcat & Atrophic & Pale & $(+)$ & Attenuated & NA & 2 \\
\hline $\begin{array}{l}\text { Patient } \\
\text { V: } \\
\text { 10/38/ } \\
\text { F }\end{array}$ & $\begin{array}{l}\text { RE: CF } \\
\text { LE: HM }\end{array}$ & $\begin{array}{l}\text { No, } \\
30 \text { years }\end{array}$ & NA & PCOcat & $\begin{array}{l}\text { Atrophic, } \\
\text { sparse } \\
\text { RPE } \\
\text { changes }\end{array}$ & $\begin{array}{l}\text { Slight } \\
\text { pallor }\end{array}$ & $\begin{array}{l}(+), \text { mid-pe- } \\
\text { ripheral } \\
\text { white dot } \\
\text { deposits }\end{array}$ & Attenuated & NA & 1 \\
\hline $\begin{array}{l}\text { Patient } \\
\text { IV: } \\
10 / 36 / \\
M\end{array}$ & BE: LP & Yes & $\begin{array}{c}\mathrm{RE}: \mathrm{S}-7.5, \\
\mathrm{C}-1.00 \\
\mathrm{LE}: \mathrm{S}-7.5 \\
\mathrm{C}-3.25\end{array}$ & PCOcat & Atrophic & $\begin{array}{l}\text { Slight } \\
\text { pallor }\end{array}$ & ++ & Attenuated & $\begin{array}{l}\text { Mid-peripheral } \\
\text { confluent lobular } \\
\text { hypofluorescence }\end{array}$ & 2 \\
\hline $\begin{array}{l}\text { Patient } \\
\text { IV: } \\
\text { 12/32/ } \\
\text { F }\end{array}$ & $\begin{array}{l}\text { RE: CF } \\
\text { LE: LP }\end{array}$ & Yes & NA & None & Atrophic & $\begin{array}{l}\text { Slight } \\
\text { pallor }\end{array}$ & Absent & Attenuated & NA & 1 \\
\hline $\begin{array}{l}\text { Patient } \\
\text { V: } \\
7 / 19 / F\end{array}$ & BE: CF & Yes & $\begin{array}{l}\text { RE:S-6.5, } \\
\text { C-3.5 } \\
\text { LE:S-10.5, } \\
\text { C-2.0 }\end{array}$ & PCOcat & $\begin{array}{l}\text { RPE } \\
\text { mottling }\end{array}$ & Healthy & $\begin{array}{l}\text { Absent, } \\
\text { mid- } \\
\text { peripheral } \\
\text { white dots }\end{array}$ & Normal & $\begin{array}{l}\text { Early macular } \\
\text { hypofluorescence } \\
\text { due to CMO with } \\
\text { late pooling, early } \\
\text { peripheral hypo- } \\
\text { fluorescence, late } \\
\text { mottled hyper- } \\
\text { fluorescence }\end{array}$ & 1 \\
\hline
\end{tabular}

Po, polar; PCO, posterior capsular opacity; A, anterior; P, posterior; NS, nuclear sclerosis; cat, cataract 
Table 2 Funduscopy and fluorescein angiography findings

\begin{tabular}{lll}
\hline Pattern & Fundus colour photography & Fluorescein angiography \\
\hline Pattern $1(n=3)$ & $\begin{array}{l}\text { 1. Healthy disk } \\
\text { 2. Macular RPE changes or cystoid macular oedema }\end{array}$ & $\begin{array}{l}\text { 1. Macula: early hypofluorescence probably due to foveal cysts } \\
\text { 2. Periphery: early hypofluorescence due to late filling of the } \\
\text { inner choroid with late irregular fluorescence due irregular } \\
\text { dying away RPE. }\end{array}$ \\
& $\begin{array}{ll}\text { 3. Normal or slightly attenuated retinal vessels } \\
\text { 4. Peripheral grey discoloration of the retina and white } \\
\text { dot deposits with virtually no clumped pigmentations }\end{array}$ \\
Pattern $2(n=7)$ Pale disc & $\begin{array}{l}\text { 1. Macula: Large partially confluent lobular area of } \\
\text { hypofluorescence in early and late frames due respectively } \\
\text { to absence of the inner choroid and cystoid macular oedema } \\
\text { 2. Periphery: annular patches masking the normal background } \\
\text { fluorescence corresponding to clumped pigmentations }\end{array}$ \\
3. Attenuated vessels & \\
4. Clumped pigmentation &
\end{tabular}

with visual acuities ranging from CF to NLP. All had congenital nystagmus decreasing with age. There was no trend towards specific refraction default. All had brown irides and all but one had posterior capsular cataract. Bilateral anterior polar cataract was found in two patients.

Patient V:14, pedigree BO, a 19-year-old myopic female with uncorrected distance visual acuity of $\mathrm{CF}$, had a blue-
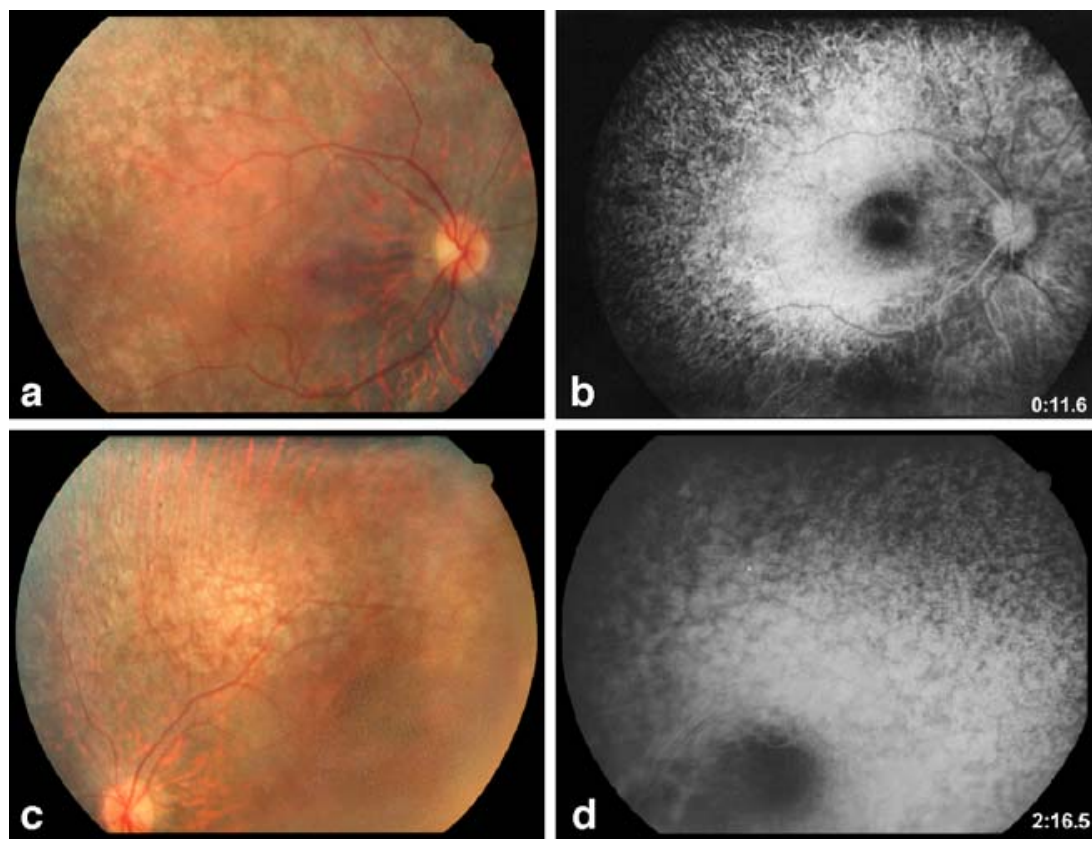

Fig. 3 Pattern 1: fundus colour photography and fluorescein angiography. a. Fundus colour photograph, right eye. Patient V:7/19/F, pedigree BO. Confluent white dot deposits and grey discoloration of the RPE localised outside the temporal vascular arcades. Peripapillary atrophy. b. Fluorescein angiogram, early frame, right eye. Patient V:7/19/F, pedigree BO. Mid-peripheral hypofluorescence caused by diffuse alteration of the RPE and lack of the choriocapillaris. Cystoid hypofluorescence in the macular area due to cystoid macular oedema. c. Fundus colour photograph, left eye. Patient

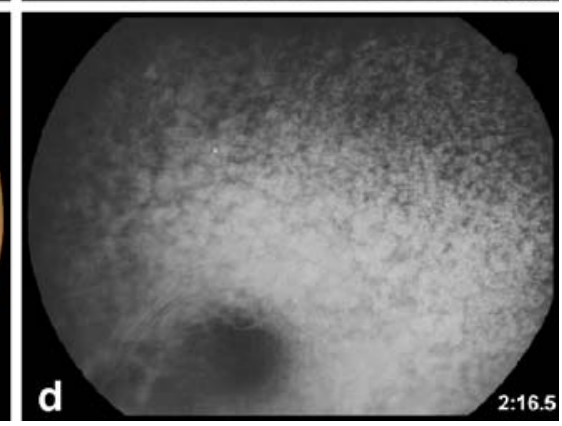
oedema yellow axis on the Farnsworth dichotomous D-15 test and the Humphrey visual field showed a partial island of central vision in the left eye. Patient V:10/38/F, pedigree $\mathrm{BH}$, and patient IV:12/32/F, pedigree $\mathrm{BO}$, were not able to perform either the Farnsworth dichotomous D-15 or the Humphrey visual field tests but could distinguish saturated red, blue, and green colours and showed very restricted confrontational

$\mathrm{V}: 7 / 19 / \mathrm{F}$, pedigree BO. As in (a). d. Fluorescein angiogram, late frame, left eye. Patient V:7/19/F, pedigree BO. Persistence of midperipheral diffuse hypofluorescence and well-delimited islands of hyperfluorescence in the posterior pole and outside the temporal vascular arcades corresponding to the area of white dot deposits and grey discoloration of the RPE demonstrated in (a) and (c). Petaloid hypofluorescence in the macular area due to cystoid macular 


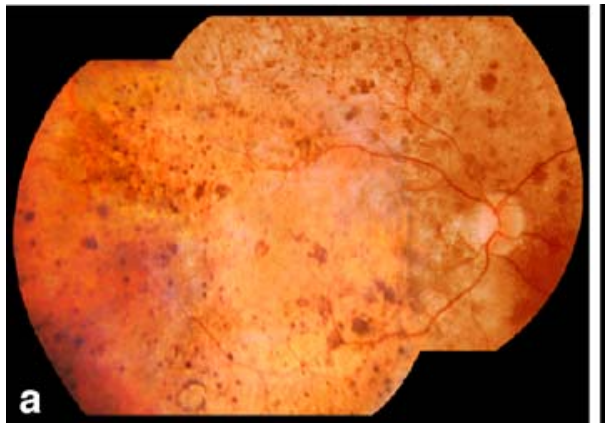

Fig. 4 Pattern 2: fundus colour photography and fluorescein angiography. a Composed fundus colour photograph, right eye. Patient IV:3/49/M, pedigree BH. Typical mid-peripheral pigmented clumps of different sizes either entirely pigmented or with central depigmentation. b Fluorescein angiogram, late frame, right eye. Patient IV:3/49/M, pedigree BH. Posterior pole confluent hypofluorescence due to alteration of the RPE and lack of the

visual fields. For the others, both colour vision and visual field were not testable.

Fundus and fluorescein angiography findings were subdivided into two patterns (Table 2). Pattern 1 included relative vascular and disc preservation, mid-peripheral deep white dot deposits, grey coloration of the peripheral retina and virtually no clumped pigmentations. Angiography $(n=1)$ showed peripheral hypofluorescence in early and late frames due to lack of choriocapillaris, midperipheral hyperfluorescence increasing during the transit, reflecting an unhealthy $\mathrm{EP}$, and partial preservation of the choriocapillaris. Hypofluorescence of the macular area may have been due to cystoid macular oedema (Fig. 3). Pattern 2 included attenuated vessels and optic disc pallor, mid-peripheral clumped pigmentation and absence of white dots. Angiography $(n=3)$ showed a lack of choriocapillaris in the periphery as well as in the posterior pole. Peripheral and central masking in the zone corresponding to clumped pigment (Fig. 4). The mean age in pattern 1 was choriocapillaris in the macular area. Masking effect at the posterior pole and mid-periphery due to clumped pigmentation. c Composed fundus colour photograph, left eye. Patient IV:2/55/F, pedigree $B H$. Typical mid-peripheral pigmented clumps of different sizes either entirely pigmented or with central depigmentation. Blurred view of the posterior pole due to lens opacities

$29 \pm 12.02$ years and in pattern $2,47 \pm 5.45$ years $(p=0.03)$. Patients in pattern 1 had better vision then pattern 2 (NS) (Table 1).

Eleven of the 13 diagnosed heterozygotes were assessed. They were aged $34-86$ years. All had normal vision, ranging from 20/50 to 20/20, except one (patient III: $1 / 65 / \mathrm{F}$, pedigree $\mathrm{BO}$ ) who was diabetic and had high myopia and age-related cataract (visual acuity OU 20/200). All had normal confrontational visual fields and none had nystagmus. Funduscopy was normal.

Both scotopic and photopic ERG responses were not detectable in the 8 homozygotes tested. ERG responses were normal in the two heterozygotes tested.

Pupillometry was performed in nine homozygotes, three heterozygotes and two wild-type controls. The controls showed normal contraction amplitude, velocity and latency. The pupil data of three members of the pedigree $\mathrm{BH}$ (patients V:7, V:3, IV:2) were excluded because inadequate numbers of reliable samples (fewer than five) were

Table 3 Pupillometry results in pedigrees $\mathrm{BH}$ and $\mathrm{BO}$

\begin{tabular}{|c|c|c|c|c|c|c|c|}
\hline \multirow[t]{2}{*}{ Patient/ age (years)/sex } & \multicolumn{2}{|c|}{ Contraction amplitude (CA) } & \multicolumn{2}{|c|}{ Latency (LAT) } & \multicolumn{2}{|c|}{ Contraction velocity (V) } & \multirow{2}{*}{$\begin{array}{l}\text { RPE65: R91W } \\
\text { mutation, } \\
\text { WT wild type }\end{array}$} \\
\hline & CA RE & CA LE & LAT RE & LAT LE & V RE & V LE & \\
\hline \multicolumn{8}{|l|}{ Pedigree $\mathrm{BH}$} \\
\hline Patient V:3/54/F & $0.01 *$ & NR & NR & NR & NR & NR & R91W/R91W \\
\hline Patient V:10/38/F & $0.49 *$ & $0.70 *$ & $0.47 *$ & $0.31 *$ & $0.59 *$ & $0.65^{*}$ & R91W/R91W \\
\hline Patient IV:4/40/F & 1.12 & 1.24 & 0.23 & 0.23 & 1.68 & 2.11 & WT/R91W \\
\hline \multicolumn{8}{|l|}{ Pedigree BO } \\
\hline Patient III:1/65/F & 1.13 & 0.99 & $0.26^{*}$ & $0.26^{*}$ & 1.64 & 1.79 & WT/R91W \\
\hline Patient IV:5/43/M & $0.63 *$ & $0.72 *$ & NR & $0.49 *$ & NR & $1.34 *$ & R91W/R91W \\
\hline Patient IV:11/34/F & 1.18 & 1.19 & 0.24 & 0.23 & 1.65 & 1.83 & WT/R91W \\
\hline Patient IV:12/32/F & 1.13 & 0.89 & $0.28 *$ & $0.28 *$ & 1.56 & 1.47 & R91W/R91W \\
\hline Patient V:7/19/F & $0.59 *$ & $0.54 *$ & $0.31 *$ & $0.42 *$ & $0.73^{*}$ & $0.60 *$ & R91W/R91W \\
\hline
\end{tabular}

*Beyond one standard deviation

*Normal ranges: contraction amplitude $0.81-1.97$; latency $\leq 0.25$; contraction velocity $\geq 1.44$ 


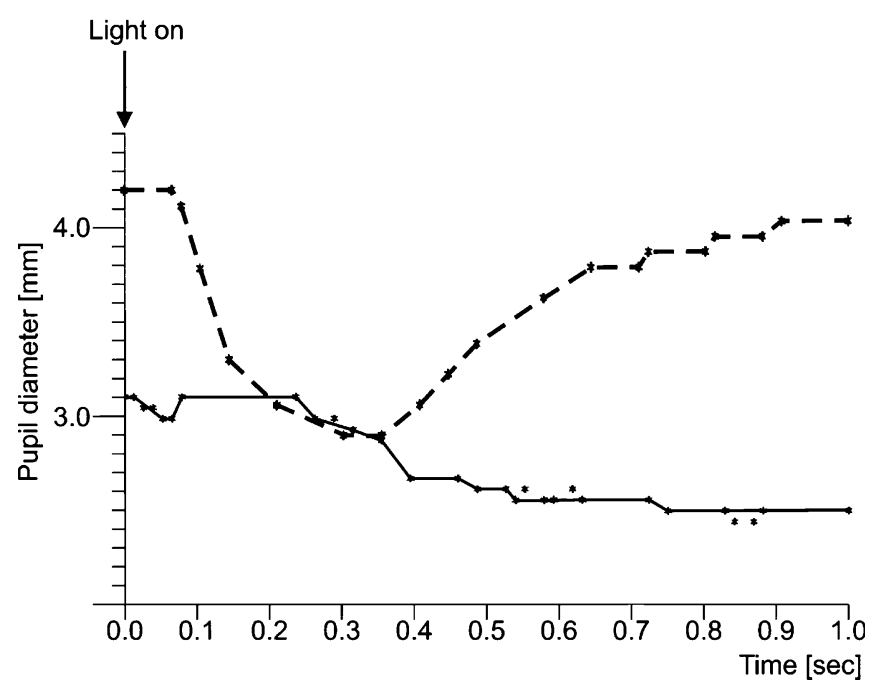

Fig. 5 Single monocular recordings to light flash in two patients (solid curve homozygote; dashed curve heterozygote)

obtained due to nystagmus. Pupillary responses of the 8 other family members ( 5 homozygotes, 3 heterozygotes) are reported in Table 3. Waveforms of an heterozygote (pedigree BO: patient IV.11) and an homozygote (pedigree BH: patient IV:3) are shown in Fig. 5. Patient V:3/54/F, pedigree $\mathrm{BH}$, showed recordable responses only in the contraction amplitude in the right eye, allowing no further conclusions. Evaluation of the pupillary light reflex revealed diminished contraction amplitude, prolonged latency time and decreased contraction velocity in three homozygotes with poor vision (two of pattern 1, one of pattern 2). One additional homozygote with visual acuity of CF RE and LP LE (patient IV:12/32/F, pedigree BO, pattern 1) had a subnormal contraction amplitude with only minimal prolongation of the pupillary latency time. Pupillometry was normal in two heterozygotes, and a third heterozygote (patient III:1/65/F, pedigree BO) who was also diabetic showed a mildly prolonged latency time.

\section{Discussion}

RPE65 mutations are a common cause of EORD [14] and may be responsible in $6.1-11.4 \%$ of patients with mutations in homozygous or compound heterozygous form $[9,26]$. The disease-causing mutation mechanism of the missense mutation R91W is not yet known but has already been reported as a recurrent mutation arising on different ethnic backgrounds [26]. This change together with the R91Q mutation was described as causing both Leber congenital amaurosis (LCA) and autosomal recessive retinitis pigmentosa in compound heterozygotes and LCA in homozygotes [14, 18]. The R91W mutation may exert its pathogenic effect by changing the tertiary structure of the protein after the replacement of arginine, a positively charged, linear strong proton donor, by tryptophan, an uncharged aromatic proton donor [3]. Specifically, Thompson et al. predicted that the substitution at arginine 91 may perturb the local beta-pleated sheet structure into an alpha helix, possibly inactivating a functional domain necessary for the synthesis of 11 cisretinal [26].

In our study of three nuclear families, we examined 53 members of whom 11 were affected, the larger series described up to date with a single homozygous RPE65 mutation. Childhood visual function in homozygotes is good enough to acquire reading in the first decade of life but deteriorates to LP by the third decade of life. They all had congenital nystagmus, night blindness and no photophobia. Restricted visual field was common to all of them and becomes non-testable by the third decade of life. Colour vision could be evaluated by the Farnsworth dichotomous D-15 test for the only patient in the second decade, indicating an initial partial preservation of the cone system. Only saturated red, green and blue colours could be recognised by the third decade and none could be distinguished by the fourth decade. All this findings suggests that $\mathrm{R} 91 \mathrm{~W}$ phenotype is initially a rod-cone dystrophy. Although visual function was reduced since early childhood, the overall performance was better than usually seen in LCA $[4,10]$. Our findings are in keeping with the previous phenotypical descriptions of RPE65 mutations in humans and dogs $[2,5,19]$ but inconsistent with findings reported in RPE65 knock-out mice [23]. One possible explanation is that the survival time of cones relates to the size of the organism, so that mice may lose their cone functionality very early, whereas it is preserved longer in dogs and humans.

Two retinal patterns in homozygotes emerged based on fundus and fluorescein angiogram. Based on the work of Moiseyev et al. [16], we postulate that the peripheral white dot deposits seen on funduscopy of pattern 1 patients may represent accumulation of retinyl esters in the RPE. Their presence should be further assessed in other RPE65 gene mutations. White dots and clumped pigment have been described in other disease-causing mutations (mutations in NR2E3, RLBP1, RDH5 genes) [17, 24, 27, 29]. The significant difference in age between the two patterns suggested that they may represent a continuum in the evolution of the disease. All homozygous patients showed a complete loss of ERG responses and an abnormal pupillary reflex. However, a recordable reflex could be obtained in some of the homozygotes, suggesting that pupillometry may be one objective means of assessing and monitoring visual function in these patients as well as in patients who may benefit from future gene therapy [1]. In contrast, heterozygous patients showed normal visual function, ERG and pupillometry. Younger siblings should be further identified and tested.

Early-onset rod-cone dystrophy along with white dot deposits and typical absent or minimal autofluorescence, as described by Lorenz et al. [13], may become extremely 
helpful criteria in the clinical diagnosis of RPE65 mutations.

In conclusion, we identified and characterised an endemic form of early onset retinal dystrophy. It presents as an early-onset rod-cone dystrophy in a highly inbred population of Cap Bon in northeastern Tunisia, due to the prevalence of a single homozygous missense R91W mutation in exon 4 of the RPE65 gene, most likely caused by a founder effect. Two patterns were identified: the white dot deposits in earlier stages and the clumped pigment in later stages may represent a continuum. Thorough phenotyping is likely to be of great assistance in identifying this patients and will give guidance for future gene therapy.

Acknowledgements RPE65 Study Group: Olfa Charfi, Corinne Kostic, Karim Baglouti, Leonidas Zografos. O.C. and K.B. are from the Hedi Rais Institute of Ophthalmology, Tunis, Tunisia; Y.A., C.K. and L.Z. from the Department of Ophthalmology, Jules Gonin Eye Hospital, University of Lausanne, Lausanne, Switzerland.

\section{References}

1. Aleman TS, Jacobson SG, Chico JD et al (2004) Impairment of the transient pupillary light reflex in Rpe65(-/-) mice and humans in Leber congenital amaurosis. Invest Ophthalmol Vis Sci 45(4):1259-1271

2. Al-Khayer K, Hagstrom S, Pauer G et al (2004) Thirty-year follow-up of a patient with Leber congenital amaurosis and novel RPE65 mutations. Am J Ophthalmol 137(2):375-377

3. Cremers FP, van den Hurk JA, den Hollander AI (2002) Molecular genetics of Leber congenital amaurosis. Hum Mol Genet 11(10):1169-1176

4. Fazzi E, Signorini SG, Scelsa B et al (2003) Leber's congenital amaurosis: an update. Eur J Paediatr Neurol 7 (1):13-22

5. Felius J, Thompson DA, Khan NW et al (2002) Clinical course and visual function in a family with mutations in the RPE65 gene. Arch Ophthalmol 120 (1):55-61

6. Gu SM, Thompson DA, Srikumari CR et al (1997) Mutations in RPE65 cause autosomal recessive childhood onset severe dystrophy. NatGenet 17 (2):194-197

7. Hamel CP, Jenkins N, Gilbert DJ et al (1994) The gene for the retinal pigment epithelium-specific protein RPE65 is localized to human $1 \mathrm{p} 31$ and mouse 3 . Genomics 20:509-512

8. Hamel CP, Jenkins N, Gilbert DJ et al (2001) Retinal dystrophies caused by mutations in RPE65: assessment of visual functions. Br J Ophthalmol 85 (4):424-427
9. Hanein S, Perrault I, Gerber S et al (2004) Leber congenital amaurosis: comprehensive survey of the genetic heterogeneity, refinement of the clinical definition, and genotype-phenotype correlations as a strategy for molecular diagnosis. Hum Mutat 23(4):306-317

10. Heckenlively JR, Foxmann SG (1988) Congenital and early onset forms of retinitis pigmentosa. In: Retinitis pigmentosa. Lippincott, Philadelphia, pp 107-149

11. Katz ML, Redmond TM (2001) Effect of Rpe 65 knockout on accumulation of lipofuscin fluorophores in the retinal pigment epithelium. Invest Ophthalmol Vis Sci 42(12):3023-3030

12. Lorenz B, Gyurus P, Preising M et al (2000) Early-onset severe rod-cone dystrophy in young children with RPE65 mutations. Invest Ophthalmol Vis Sci 41(9):2735-2742

13. Lorenz B, Wabbels B, Wegscheider E et al (2004) Lack of fundus autofluorescence to 488 nanometers from childhood on in patients with earlyonset severe retinal dystrophy associated with mutations in RPE65. Ophthalmology 111(8):1585-1594

14. Lotery AJ, Namperumalsamy P, Jacobson SG et al (2000) Mutation analysis of 3 genes in patients with Leber congenital amaurosis. Arch Ophthalmol 118(4):538-543

15. Miller SA, Dykes DD, Polesky HF (1988) A simple salting out procedure for extracting DNA from human nucleated cells. Nucleic Acids Res 16:1215

16. Moiseyev G, Crouch RK, Goletz P et al (2003) Retinyl esters are the substrate for isomerohydrolase. Biochemistry 42 (7):2229-2238
17. Morimura H, Berson EL, Dryja TP (1999) Recessive mutations in the RLBP1 gene encoding cellular retinaldehyde-binding protein in a form of retinitis punctata albescens. Invest Ophthalmol Vis Sci 40(5):1000-1004

18. Morimura H, Fishman GA, Grover SA et al (1998) Mutations in the RPE65 gene in patients with autosomal recessive retinitis pigmentosa or Leber congenital amaurosis. Proc Natl Acad Sci U S A 17;95(6):3088-3093

19. Narfstrom K, Katz ML, Bragadottir R et al (2003) Functional and structural recovery of the retina after gene therapy in the RPE65 null mutation dog. Invest Ophthalmol Vis Sci 44(4):1663-1672

20. Paunescu K, Wabbels B, Preising MN et al (2005) Longitudinal and crosssectional study of patients with earlyonset severe retinal dystrophy associated with RPE65 mutations. Graefes Arch Clin Exp Ophthalmol 243 (5):417-426

21. Poehner WJ, Fossarello M, Rapport AL et al (2000) A homozygous deletion in RPE65 in a small Sardinian family with autosomal recessive retinal dystrophy. Mol Vis 6:192-198

22. Redmond TM, Yu S, Lee E et al (1998) RPE65 is necessary for production of 11 cis vitamin $A$ in the retinal cycle. Nat Genet 20:344-351

23. Seeliger MW, Grimm C, Stahlberg F et al (2001) New views on RPE65 deficiency: the rod system is the source of vision in a mouse model of Leber congenital amaurosis. Nat Genet 29 (1):70-74 
24. Sharon D, Sandberg MA, Caruso RC et al (2003) Shared mutations in NR2E3 in enhanced S-cone syndrome, Goldmann-Favre syndrome, and many cases of clumped pigmentary retinal degeneration. Arch Ophthalmol 121 (9):1316-1323

25. Simovich MJ, Miller B, Ezzeldin $H$ et al (2001) Four novel mutations in the RPE65 gene in patients with Leber congenital amaurosis. Hum Mutat 18 (2):164
26. Thompson DA, Gyurus P, Fleisher LL et al (2000) Genetics and phenotypes of RPE65 mutations in inherited retinal degeneration. Invest Ophthalmol Vis Sci 41(13):4293-4299

27. To KW, Adamian M, Jakobiec FA et al (1996) Clinical and histopathologic findings in clumped pigmentary retinal degeneration. Arch Ophthalmol 114 (8):950-955

28. Veske A, Nillson SE, Narfstrom K et al (1999) Retinal dystrophy of Swedish briard/briard-beagle dogs is due to 4-bp deletion in the RPE65. Genomics 57:57-61
29. Yamamoto H, Simon A, Eriksson U et al (1999) Mutations in the gene encoding 11-cis retinol dehydrogenase cause delayed dark adaptation and fundus albipunctatus. Nat Genet 22 (2):188-191

30. Yzer S, van den Born LI, Schuil J et al (2003) A Tyr368His RPE65 founder mutation is associated with variable expression and progression of early onset retinal dystrophy in 10 families of a genetically isolated population. J Med Genet 40:709-713 